\title{
CARTA DE COLONIA
}

JOSÉEMUÑIZ MAS Barcelona
Hamburgo, 17/02/04. De nuevo utilizo la modalidad de salida lanzada para contaros algunas cosillas nuevas. Creo que en mi ultima carta no os hablé de mi viaje a Colonia. Me fui utilizando la Mitfahrerzentrale que aquí sí que existe, no como en España, donde he oído hablar de la existencia de algo similar, pero jamás he conocido a nadie que lo hubiese utilizado. Hamburgo - Colonia, $25 €$ ida y $25 €$ vuelta.
A la hora de la cita en el centro de Hamburgo hacía más calor que ningún otro día. Tenía mucha curiosidad por saber qué coche me llevaría. Hamburgo es la ciudad de los cochazos. Ya me veía en vuelo rasante por alguna de las tan cacareadas autopistas alemanas. A lomos de un Audi o un Mercedes, cuando de pronto llega una chica ala oficina, habla con el empleado y éste me señala. La chica me mira sonriente se presenta y salimos fuera. No me lo podía creer cuando se acercó a un Cinquecento, el coche más pequeño del mercado, un carrito para la compra.

La chica es rubia y delgada, pero con el mismo sex-appeal que un bocadillo de mortadela, más bien parece una pastora de una iglesia evangélica. También llega una pareja. Son turcos. Él es bastante mayor que ella, pero es su marido. Actúa del rollo «es mía y sólo mía», la abraza estrujándola más que como una demostración de cariño como un aviso. A mí me echa un vistazo como el que echaría Atatürk a sus enemigos.

La conductora habla inglés bastante bien., menos mal. Me senté delante y fuimos charlando todo el camino. Fue un agradable viaje de unas cinco horas. La chica turca parece una modosita campesina y sólo habla alemán. No exagero si digo que durante el viaje, el viejo la llama cada veinte minutos y habla con ella durante diez. En total hablan durante horas.

Llegamos a Colonia y empezamos a atravesarla en dirección a la estación central. Intento formarme una idea preliminar. Sólo consigo una. Algunos objetos del mobiliario urbano, sobre todo los indicadores de tráfico, hace tiempo que en Barcelona habrían sido sustituidos por otros más modernos.

Aquí como en todas las ciudades alemana que he visto no hay grandes calles de seis y ocho carriles en un sentido como en la Gran Vía de Barcelona. Todo es más recoleto.
Llegamos a la estación. Está atestada de gente de todos los colores, nacionalidades y condiciones que camina en todas direcciones a buen paso. Cada persona se dirige hacia un lugar determinado, pero visto desde fuera sólo se percibe una masa en movimiento, como las hormigas.

Atravieso la Terminal y salgo por la parte de atrás. Intento concentrarme al máximo en lo que veo. Me da la sensación de ser una cámara que filma la primera secuencia de una película. La cámara enfoca una puerta y ésta se abre a un inmenso decorado en el que el director no ha escatimado detalle. Hay un quiosco regentado por dos rollizas teutonas que venden salchichas. $\mathrm{Me}$ compro una y me siento en las escaleras del Dom, que si bien es impresionante, no es tan interesante como mirar a la gente.

Me como la salchicha y me pongo en movimiento hacia la casa de Achim. A los veinte minutos de llegar a Colonia, ya estoy en la zona. Aún así, estoy un poco despistado y pregunto a una señora cargada con una bolsa de frutas, que calurosamente se brinda a acompañarme. Una señora muy agradable, estuve a punto de darle un beso.

Llego a casa de Schachbrett y Claudia. ¡Y flipa, nen! La verdad es que se está muy a gusto allí, pero al $95 \%$ de la población del planeta le daría un soponcio entrar allí. [...] Mención especial merece su colección de fetiches papales, souvenirs, objetos de merchandising, cualquier cosa de Juan Pablo II. Está por todos los lados. [...] Hay una estancia general en la que se podría vivir durante meses sin salir de allí, montañas de vídeo,

"...Deambula por la sala, se sube
a una silla, se baja, se vuelve a subir,
se baja los pantalones y enseña
sus partes, se va casi hasta la calle
o toca desde el cuarto de baño
que está en el sótano... "

libros, revistas, solarium, sauna, pequeño gimnasio, cama de agua... no falta detalle para un completo disfrute hedonístico.

Nada más llegar, nos fuimos a un con cierto punki muy simpático. En un lugar donde viven acampados en carretas unos «pies negros". Birra muy barata y ningún problema para fumar kikis.

Por la noche me llevan a cenar a un sitio típico de Colonia. Grandes mesas llenas de alemanes que brindan entre grandes risotadas. Los camareros cargan con un curioso artilugio para transportar varios vasos de cerveza a la vez. Sin que pidamos nada, se acerca un camarero y nos coloca en la mesa tres vasos pecjueños de cerveza. El sitio es muy bullicioso y los camareros no dejan de dar vueltas a las mesas reponiendo los pequeños rasos de cerveza vacíos. La comida llega a través de un montacargas.

Una vez salidos del bar, damos una vuelta en bici y volvemos a casa.[...].

Al día siguiente... «el concierto". Después de comer; llega Martin. Debe tener cincuenta y algunos. Viste de blanco impecable. Por completo, hasta la gorra. Muy requeteplanchado él. Lleva consigo una ajada funda de trompeta. Es bajito y enjuto.

Al rato llega otro cuyo nombre no recuerdo. Tiene pinta de chaladillo. Sin a feitar, vestido de cualquier manera, en contraste con la pulcritud de Martin. Es un manojo de nervios. Es de los 




trabajo y el saxo de Techler.

En cuanto empiezan compruebo que no se trata exactamente dehacer música al uso. Es algo distinto. Achim no lleva la más mínima cadencia, aporrea la batería bajo posesión diabólica. De hecho no sólo golpea los pellejos del instrumento sino que lo golpea todo él. Martin y su trompeta se transforman en un manojo de nervios convulsos. Entra en trance por completo. A veces se tira al suelo $y$ toca entre espasmos en posición fetal. El contrabajista es un tipo vestido con ropa de ter-

que hablan con una mano en la coronilla y con la otra en la barbilla.

Nos vamos en el coche de Claudia, un destartalado Peugeot rojo. Claudia va espectacular, completamente vestida de de rojo y sobre unos randes zapatos rojos. En Claudia todo es grande.

Düsseldorf está muy cerca de Colonia. A la media hora por autopista, llegamos a un local que claramente en su día había sido un concesionario de coches. Pero en la planta baja completamente acristalada no hay coches, hay una exposición de cuadros e instalaciones.

En una esquina, Achim comienza a montar su batería mientras llega el resto del grupo. Me presenta a Techler, personaje ( harto curioso que «toca el saxofón». Todos «tocan» algo. Dos baterías, Achim y otro artista local, Mundt creo. Martin a la trompeta y la flauta. Una tuba, un con- gal pasadísima de moda. Lleva gorra de cateto y tiene una actitud distraída.

Para describir a Techler no tengo palabras. También poseído. Por supuesto, como el resto, toca sin importarle un carajo lo que tocan sus compañeros. Deambula por la sala, se sube a una silla, se baja, se vuelve a subir, se baja los pantalones ta la calle o toca desde el cuarto de baño que está en el sótano.

Él y Achim con su batería son lo mejor. Son como una banda de pueblo desaforada, pero a lo bestia y rollo underground. La verdad es que me pareció muy divertido.

Achim me había prevenido de que por lo regular terminan tocando sin público. Y en realidad, si nadie se lo impide, podrían toy enseña sus partes, se va casi has- car durante horas y horas. Efectivamente, tras dos horas, no aflojan el ritmo, sobre todo Achim, que debe perder un par de kilos por concierto, y el público comienza a marcharse, aunque no por completo. Al final, viendo que aquello no acababa nunca, el organizador tuvo que pedirles que pararan. Se puso delante de Techler a gesticular mientras que éste redoblaba los soplidos en la cara del tipo. Tuvo que perseguir a Techler por la sala para que se callara de una vez, ya por último con cajas destempladas.

El de la tuba, se me olvidaba, sólo daba grandes soplidos al instrumento, de dos en dos, como un barco que saluda al público que lo recibe en el muelle. Al día siguiente, Techler llamó a Achim para comentar el concierto y ambos convinieron en que el de la tuba hacía demasiado poco ruido o poco convulso. [...]

Me parece cada día más que me quedaré bastante tiempo en Alemania [...]

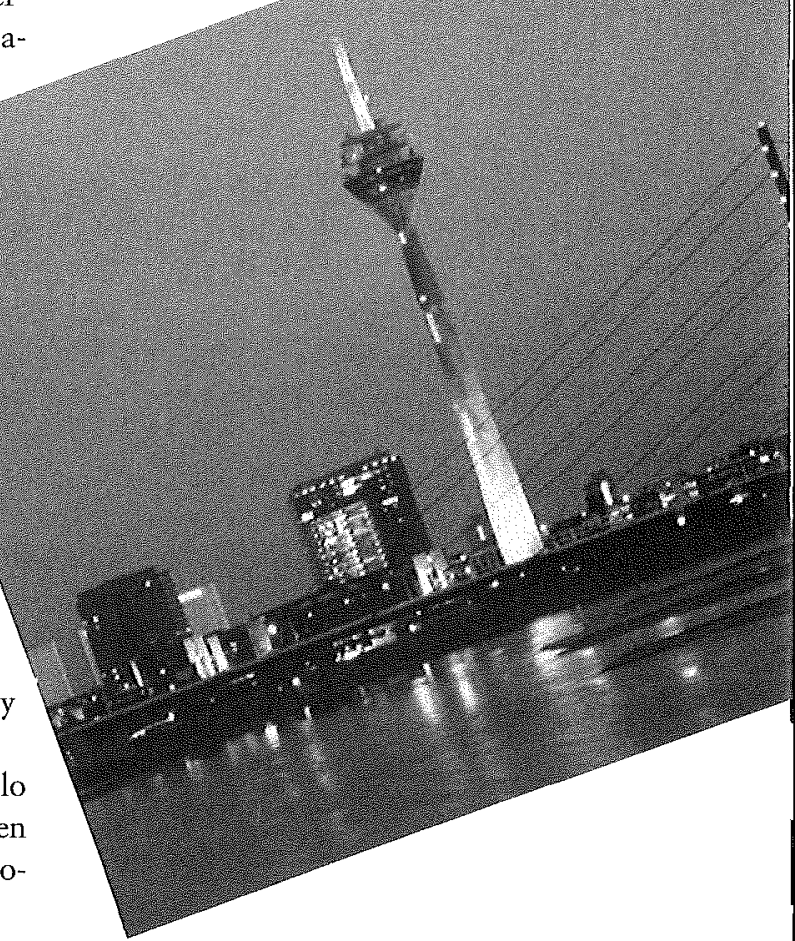

